\title{
Takotsubo cardiomyopathy complicating acute pancreatitis: a case report
}

\author{
John Yeh ${ }^{*}$ (i) and James Carroll
}

\begin{abstract}
Background: Acute pancreatitis as a trigger of Takotsubo cardiomyopathy has been infrequently described in the literature. Misdiagnosis of this phenomenon can often occur due to overlap in symptomology, particularly in those outside of the usual patient demographic.

Case presentation: A 27-year-old man with a history of alcohol abuse presented with epigastric and chest pain. Electrocardiography showed ischemic changes, and laboratory workup revealed elevated lipase and troponin. He was diagnosed with acute pancreatitis and managed presumptively as acute coronary syndrome. Subsequent coronary angiography was negative for obstructive coronary artery disease, and left ventriculography demonstrated basal hyperkinesis and apical akinesis, characteristic of Takotsubo cardiomyopathy.
\end{abstract}

Conclusions: Takotsubo cardiomyopathy is a rare complication of acute pancreatitis. Increased awareness of this phenomenon is required to prevent delays in diagnosis and avoid unnecessary interventions and complications.

Keywords: Acute alcoholic pancreatitis, Takotsubo cardiomyopathy, Case report

\section{Background}

Takotsubo cardiomyopathy (TCM) has increasingly gained international awareness since it was first introduced in 1990 [1]. Whilst there are many well-documented triggers of TCM, the role of acute pancreatitis has been only sporadically mentioned in the literature. Increasing awareness of this phenomenon particularly in those outside of the usual patient demographic may lead to earlier diagnosis and avoid unnecessary interventions. We present a rare case of TCM complicating acute alcoholic pancreatitis.

\section{Case presentation}

A 27-year-old Indigenous man, with a history of smoking and no other cardiac risk factors, developed epigastric pain associated with nausea, vomiting and diaphoresis, following significant alcohol consumption the night prior.

*Correspondence: chia-han.yeh@health.qld.gov.au

Institute of Surgery, Townsville Hospital and Health Service, 100 Angus

Smith Drive, Douglas, Townsville, QLD 4814, Australia
In the subsequent hours he also developed chest pain. On presentation he was tachycardic to 110 beats per minute, febrile to $38.4{ }^{\circ} \mathrm{C}$, and had epigastric tenderness.

His laboratory workup showed an elevated lipase of $1310 \mathrm{U} / \mathrm{L}$, leukocytosis of $17.2 \times 10^{9} / \mathrm{L}, \mathrm{C}$-reactive protein of $26 \mathrm{mg} / \mathrm{L}$, and marginally deranged liver function tests with bilirubin of $26 \mu \mathrm{mol} / \mathrm{L}$, alkaline phosphatase of 118 $\mathrm{U} / \mathrm{L}$, gamma-glutamyl transpeptidase of $101 \mathrm{U} / \mathrm{L}$, alanine aminotransferase of $109 \mathrm{U} / \mathrm{L}$, and aspartate aminotransferase of $141 \mathrm{U} / \mathrm{L}$. Kidney function was maintained with a creatinine of $76 \mu \mathrm{mol} / \mathrm{L}$, and his lipid profile showed only raised triglycerides at $2.5 \mathrm{mmol} / \mathrm{L}$. His serial troponins rose from $0.77 \mathrm{ng} / \mathrm{mL}$ to $1019.63 \mathrm{ng} / \mathrm{mL}$, and electrocardiography (ECG) revealed ST elevation in the anterior leads (Fig. 1). A provisional diagnosis of anterior ST-elevation myocardial infarction was made. The patient was thrombolysed, commenced on dual antiplatelet therapy and low-molecular weight heparin, and transferred to the Coronary Care Unit of the closest tertiary centre.

Repeat ECG showed partial resolution of ST-elevation and the presence of $\mathrm{Q}$ waves. Transthoracic 


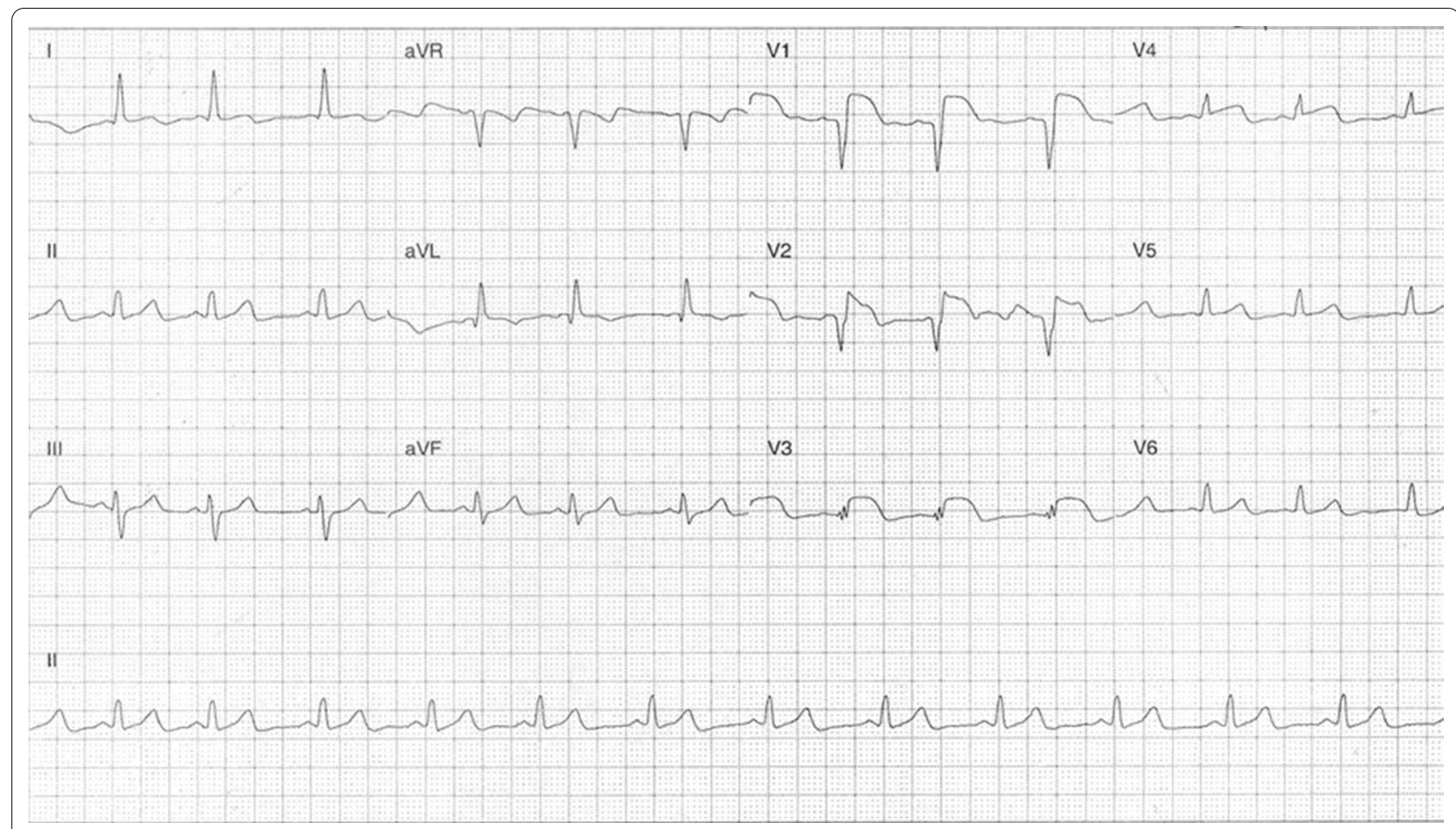

Fig. 1 Electrocardiography. ST elevation in leads V1-V3

echocardiography demonstrated severely reduced left ventricular systolic function, with an estimated ejection fraction of $20 \%$. Subsequent coronary angiography with ventriculography showed non-obstructive coronary artery disease, and basal hyperkinesis with apical akinesis of the left ventricle (Fig. 2). The final diagnosis of TCM was made. Dual antiplatelet therapy was ceased, and the patient was commenced on an angiotensinconverting enzyme inhibitor (ACEi) and beta-blocker.

Meanwhile, hepatobiliary ultrasound was unrevealing for cholelithiasis or choledocholithiasis, and computed tomography of the abdomen demonstrated an oedematous pancreas with diffuse peripancreatic fat stranding. There were no signs of necrosis, collections or vascular complications (Fig. 3). Therefore, the patient was concurrently diagnosed with uncomplicated acute alcoholic pancreatitis. This was managed conservatively with intravenous fluids and gradual diet upgrade. The patient's abdominal pain resolved after three days.

The patient was discharged on day five. On initial follow-up at four weeks he had moderate clinical recovery, and still became dyspnoeic on heavy lifting or several minutes of walking. He had ceased further alcohol use. Follow-up with repeat echocardiography was planned at three months, but the patient did not attend.

\section{Discussion and conclusions}

TCM is characterised by transient left ventricular wall abnormality resulting in apical ballooning resembling an octopus trap, 'takotsubo'. Most cases of TCM are associated with a preceding stressor, and sympathetic stimulation in the setting of increased catecholamines is widely accepted to be central to its pathogenesis. Classically, this association has been with emotional trauma-that is the 'broken heart'; however physical stressors are in fact more common. These include various physical activities, procedures, drugs, and medical conditions ranging from sepsis to lightning strike [2].

Acute pancreatitis as a trigger of TCM is a rare phenomenon. Since it was first described in 2007 [3], there have been only 11 total cases reported in the literature (Table 1). Of these, 9 were female, with ages ranging between 47 and 76 years and a median of 63 years, and $82 \%$ of cases above 50 years. This corresponds with the usual demographic of TCM, which is the postmenopausal woman [2]. Additionally, the aetiology of pancreatitis reflects that typically seen in the community, with alcohol and gallstones predominating. The timeframe for onset of pancreatitis symptoms to TCM was quite variable, ranging from hours to 7 days. Similarly, the markers of systemic inflammation were 


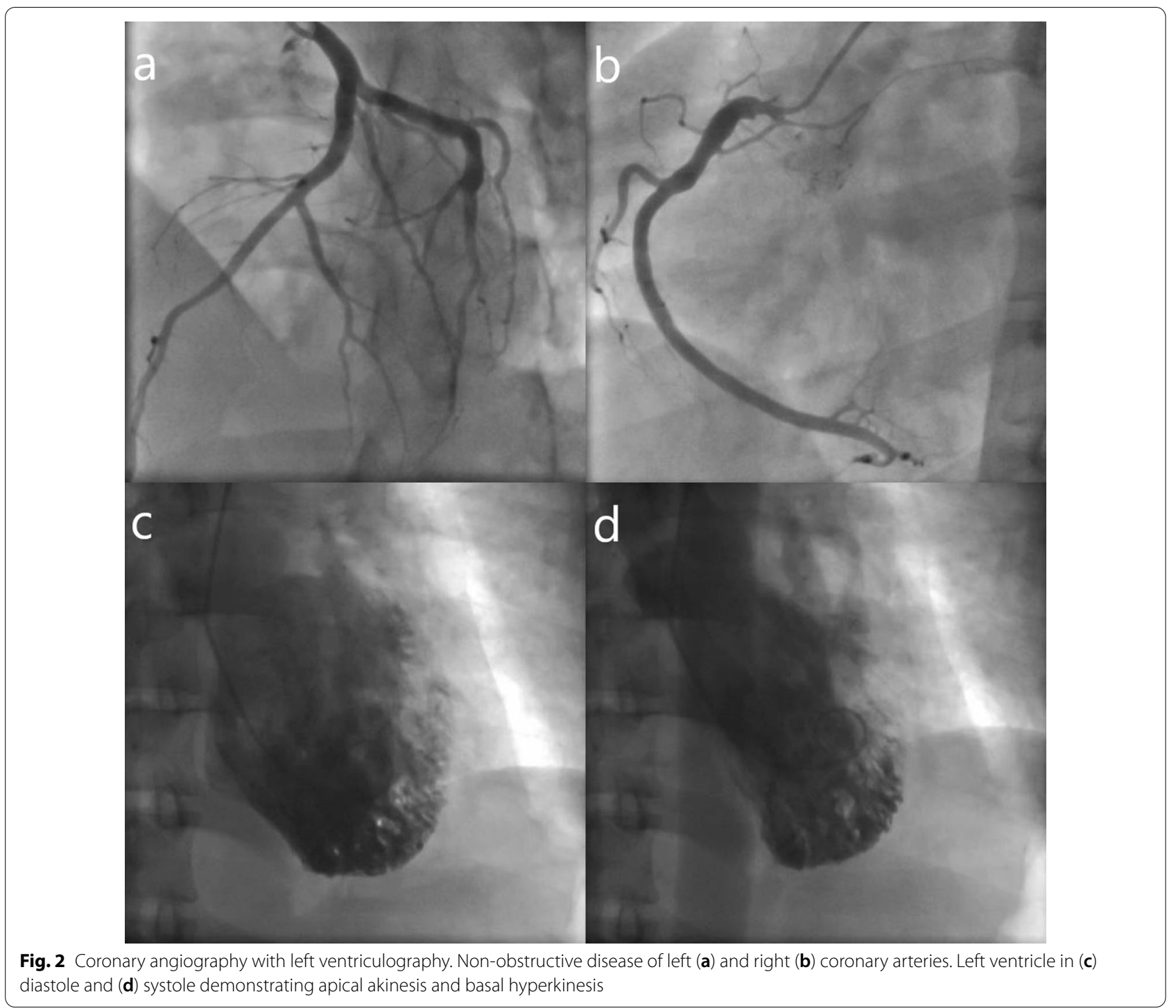

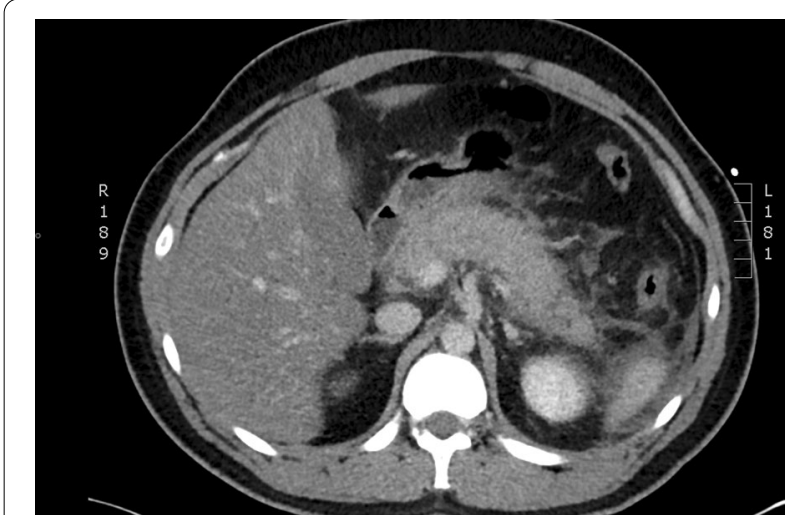

Fig. 3 Abdominal computed tomography. Pancreatic oedema with surrounding fat stranding an unreliable predictor of development of TCM or its complications, with leukocytosis ranging from mild to markedly elevated.

Recognising TCM in the setting of pancreatitis is clinically difficult. With the exception of two cases which manifested as cardiac arrest [7, 12], TCM complicating pancreatitis results in considerable overlap in symptomology, and a patient's epigastric pain can easily mask or distract from chest pain. Formal diagnosis of TCM relies heavily on coronary angiography with left ventriculography. While multiple diagnostic criteria have been proposed, the most widely known is the Revised Mayo Clinic Criteria [2]. This requires the presence of transient left ventricular dysfunction, the absence of obstructive coronary artery disease, electrocardiographic abnormalities or troponin elevation, 


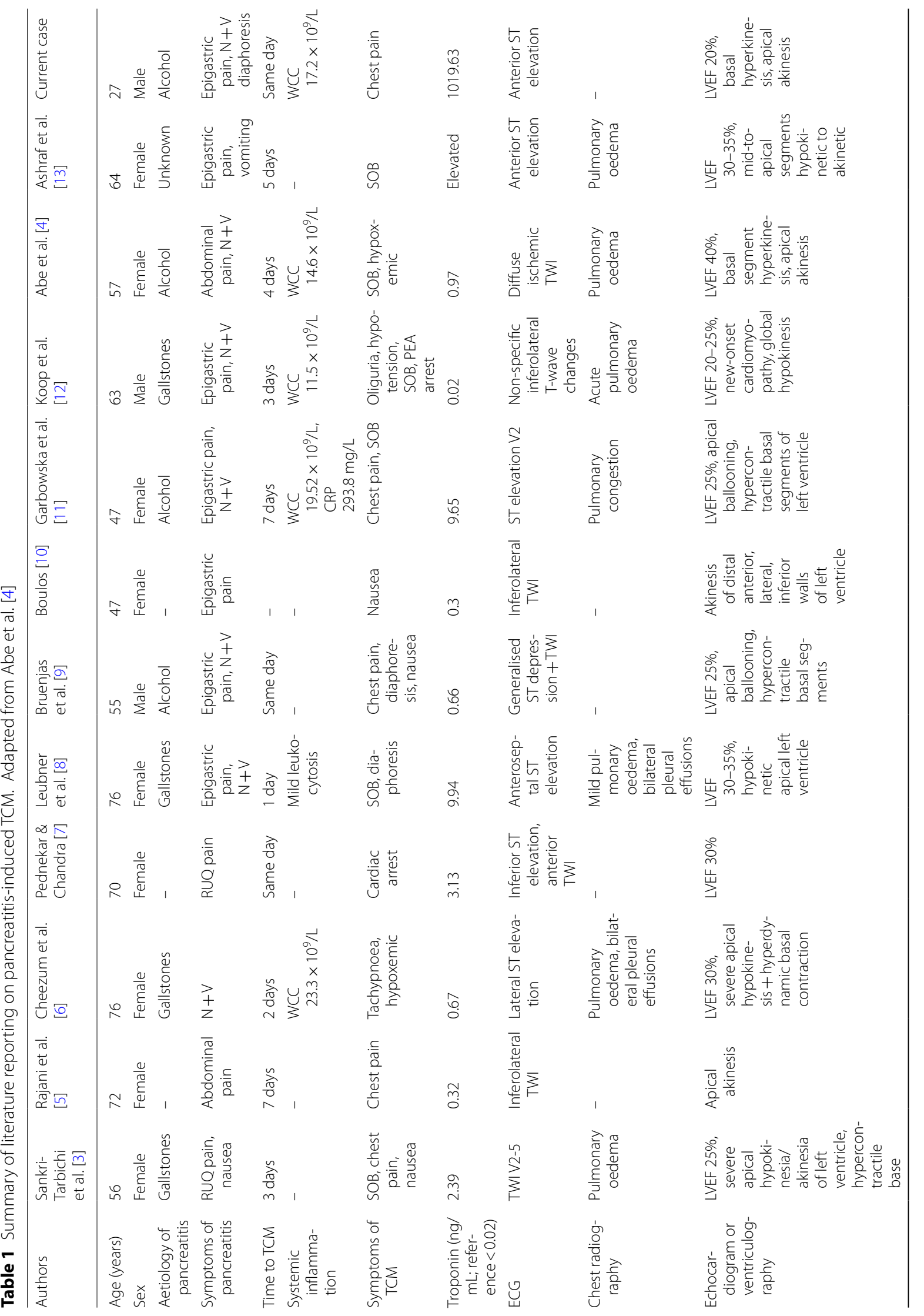




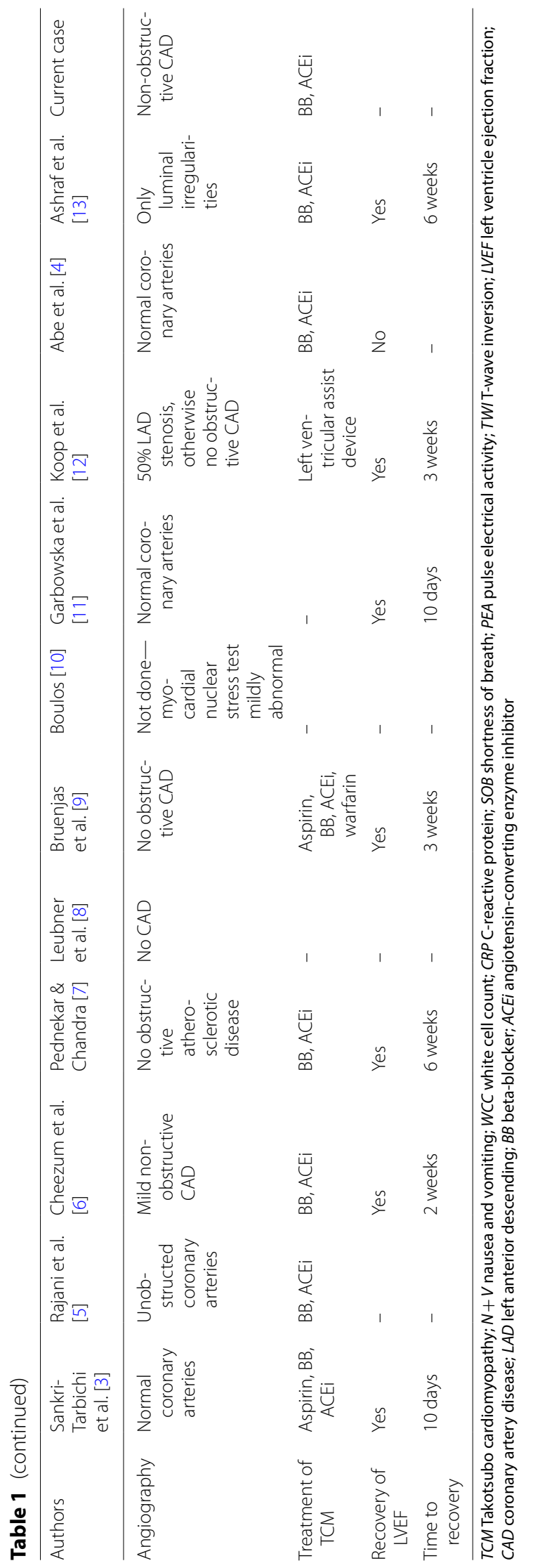


and the absence of pheochromocytoma and myocarditis [14]. Indeed, all previously reported cases of pancreatitis-induced TCM, and our own case, had elevated troponin, and ECG almost always demonstrated ST elevation or T-wave inversion. Chest radiography, when performed, showed features of acute pulmonary oedema. Furthermore, almost all cases demonstrated left ventricular apical hypokinesis or akinesis, basal hyperkinesis, reduced ejection fraction, and normal or non-obstructive coronary arteries (Table 1).

Further diagnostic challenge lies in the overlap of biochemical and ECG changes of TCM with those of acute coronary syndrome. Our presented case, like several others, was diagnosed presumptively as acute coronary syndrome and treated as such $[5,9]$. Emergency reperfusion therapy with thrombolysis, whilst not inappropriate for this patient given the considerable delay in reaching cardiac catheterisation, is not without significant risks of bleeding and stroke [15]. However, in a centre where primary percutaneous coronary intervention was available within $90 \mathrm{~min}$, a diagnosis of TCM could have been reached sooner, and the potential complications of thrombolysis could have been avoided [16]. Interestingly, there may be a role in the stable patient for early echocardiogram and subsequent computed tomography coronary angiography to reach a diagnosis of TCM, thereby avoiding the vascular complications of cardiac catheterisation [16].

The outcomes of TCM as a complication of pancreatitis appear to be good. There has been no reported deaths, even in the severe case of cardiac arrest ultimately requiring left ventricular assist device [12]. All patients, where treatments were described, were discharged on a beta-blocker and ACEi, and in those whose follow-up was reported, all but one had recovered left ventricular function, ranging from as early as 10 days up to 6 weeks. Abe et al. [4] reported the case of persistently reduced left ventricular function even at 4 months, which was hypothesised to be due to ongoing alcohol use (Table 1).

Overall, TCM is a rare, and potentially under-recognised, complication of acute pancreatitis. In a scenario where delays in diagnosis can lead to unnecessary interventions and complications, increasing awareness of this phenomenon by surgeons and physicians alike is imperative.

\footnotetext{
Abbreviations

TCM: Takotsubo cardiomyopathy; ECG: Electrocardiography; ACE: Angiotensinconverting enzyme; N + V: Nausea and vomiting; WCC: White cell count; CRP: C-reactive protein; SOB: Shortness of breath; PEA: Pulseless electrical activity; TWI: T-wave inversion; LVEF: Left ventricle ejection fraction; CAD: Coronary artery disease; LAD: Left anterior descending; BB: Beta-blocker.
}

\section{Acknowledgements}

None.

\section{Authors' contributions}

$J C$ conceptualised this case report and JY performed the literature search. The manuscript was drafted by JY and proofed by JC. Both authors read and approved the final manuscript.

\section{Funding}

This research did not receive any specific grant from funding agencies in the public, commercial, or not-for-profit sectors.

\section{Availability of data and materials}

All data generated or analysed during this study are included in this published article.

\section{Declarations}

Ethics approval and consent to participate

Informed consent was obtained from the patient.

\section{Consent for publication}

Written informed consent was obtained from the patient for publication of this case report and any accompanying images. A copy of the written consent is available for review by the Editor of this journal.

\section{Competing interests}

The authors declare that they have no competing interests.

Received: 19 October 2020 Accepted: 17 March 2021

Published online: 23 March 2021

\section{References}

1. Sato H. Tako-tsubo-like left ventricular dysfunction due to multivessel coronary spasm. In: Kodama K, Haze K, Hori M, editors. Clinical aspect of myocardial injury: from ischemia to heart failure. Tokyo: Kagakuhyoronsha Publishing Co; 1990. p. 56-64.

2. Ghadri JR, Wittstein IS, Prasad A, Sharkey S, Dote K, Akashi YJ, et al. International expert consensus document on takotsubo syndrome (Part I): clinical characteristics, diagnostic criteria, and pathophysiology. Eur Heart J. 2018;39:2032-46.

3. Sankri-Tarbichi AG, Mathew PK, Matos M, His D. Stress-related cardiomyopathy. Heart Lung. 2007;36:43-6.

4. Abe T, Simien M, Dolphurs H. Acute pancreatitis complicated by stress cardiomyopathy with persistent apical akinesis: a case report and literature review. J Investig Med High Impact Case Rep. 2019;7:2324709619893197

5. Rajani R, Przedlacka A, Saha M, Belder A. Pancreatitis and the broken heart. Eur J Emerg Med. 2010;17:27-9.

6. Cheezum MK, Willis SL, Duffy SP, Moawad FJ, Horwhat JD, Huffer LL, et al. Broken pancreas, broken heart. Am J Gastroenterol. 2010;105:327-8.

7. Pednekar M, Chandra P. Sudden cardiac death from takotsubo cardiomyopathy triggered by acute pancreatitis. J Hosp Med 2010;5.

8. Leubner JK, Ortiz Z, Wolfrey J, Drake L. Can Gallstones Break the Heart? Pancreatitis-induced Takotsubo cardiomyopathy mimicking acute myocardial infarction. J Am Geriatr Soc. 2014;62:1814-5.

9. Bruenjes JD, Vallabhajosyula S, Vacek CJ, Fixley JE. Acute pancreatitisinduced takotsubo cardiomyopathy in an African American Male. ACG Case Rep J. 2015:3:53-6.

10. Boulos P. An inflamed pancreas and a broken heart: pancreatitis-induced Takotsubo cardiomyopathy. J Hosp Med. 2015;10:A349.

11. Garbowska M, Kurek K, Sobkowicz B. Takotsubo cardiomyopathy resulting from exacerbation of chronic pancreatitis. Folia Cardiol. 2016;11:473-6.

12. Koop AH, Bailey RE, Lowman PE. Acute pancreatitis-induced Takotsubo Cardiomyopathy and Cardiogenic Shock Treated With a Percutaneous Left Ventricular Assist Device. BMJ Case Rep 2018:bcr2018225877. 
13. Ashraf S, Lam K, Hu G. When your pancreas breaks your heart: a case of pancreatitis induced Takotsubo Cardiomyopathy. Am J Respir Crit Care Med. 2019;199:A3568.

14. Prasad A, Lerman A, Rihal CS. Apical ballooning syndrome (Tako-Tsubo or stress cardiomyopathy): a mimic of acute myocardial infarction. Am Heart J. 2008;155:408-17.

15. Chew DP, Scott IA, Cullen L, French JK, Briffa TG, Tideman PA, et al.

National Heart Foundation of Australia \& Cardiac Society of Australia and New Zealand: Australian Clinical Guidelines for the Management of Acute Coronary Syndromes 2016. Heart Lung Circ. 2016;25:895-951.
16. Ghadri JR, Wittstein IS, Prasad A, Sharkey S, Dote K, Akashi YJ, et al. International expert consensus document on Takotsubo syndrome (part II): diagnostic workup, outcome, and management. Eur Heart J. 2018;39:2047-62.

\section{Publisher's Note}

Springer Nature remains neutral with regard to jurisdictional claims in published maps and institutional affiliations.
Ready to submit your research? Choose BMC and benefit from:

- fast, convenient online submission

- thorough peer review by experienced researchers in your field

- rapid publication on acceptance

- support for research data, including large and complex data types

- gold Open Access which fosters wider collaboration and increased citations

- maximum visibility for your research: over $100 \mathrm{M}$ website views per year

At BMC, research is always in progress.

Learn more biomedcentral.com/submissions 